\title{
Increase in digyny explains polyploidy after in-vitro fertilization of frozen-thawed mouse oocytes
}

\author{
J. Carroll, G. M. Warnes and C. D. Matthews \\ Department of Obstetrics and Gynaecology, The University of Adelaide, \\ The Queen Elizabeth Hospital, Woodville Road, Woodville, South Australia 5011, Australia
}

\begin{abstract}
Summary. Fewer frozen-thawed mouse oocytes cleaved to the 2-cell stage compared to fresh control oocytes fertilized in vitro $(46 \%$ vs $79 \%)$. The reduced rate of 2 -cell formation was only partly explained by a decreased rate of fertilization $(63 \%$ vs $85 \%)$. However, subsequent development to expanded blastocysts was not different $(75 \% \mathrm{vs}$ $78 \%$ ). An increased frequency of second polar body retention by fertilized frozenthawed oocytes compared with controls $(11.8 \%$ vs $1 \cdot 3 \%)$ was shown to be largely responsible for the higher incidence of polyploidy $(16 \cdot 3 \%$ vs $3.7 \%)$. The frequency of polyspermic fertilization was not different in the two groups $(3.9 \%$ vs $2 \cdot 3 \%)$.
\end{abstract}

Keywords: cryopreservation; in-vitro fertilization; mouse; oocyte; digyny; polyploidy

\section{Introduction}

The widespread use of superovulation regimens in human in-vitro fertilization programmes has resulted in an increased number of oocytes being recovered and embryos produced after fertilization in vitro (Trounson et al., 1981). Since the number of eggs/embryos transferred is usually limited to 3 or 4 due to the increased potential for multiple pregnancies, surplus embryos are generally frozen and transferred in a later cycle, a technique which may improve the overall expectation of pregnancy from a single stimulated cycle. As a consequence of the considerable ethical and legal concerns associated with human embryo freezing a substantial interest currently exists in preserving the unfertilized human oocyte. A few human pregnancies have been reported after fertilization and transfer of frozen-thawed oocytes (Chen, 1986; Al Hasani et al., 1987; Van Vem et al., 1987).

The requirement of oocytes to undergo normal fertilization following cryopreservation is, however, associated with a number of specific problems not encountered with embryo freezing. Glenister et al. (1987) demonstrated that, while freezing and thawing of mouse oocytes did not cause an increase in aneuploidy, there was a halving of the fertilization rate and a doubling of the frequency of polyploidy. Similar observations have been reported with human oocytes (Al Hasani et al., 1987). Whether the source of polypoidy is due to polyspermic fertilization or the retention of the second polar body is currently unclear. In this study, we have investigated the in-vitro fertilization and development of embryos derived from frozen-thawed mouse oocytes; in particular, we have addressed the reason for the reduced ability of frozen-thawed oocytes to undergo fertilization and have focussed attention on the source of polyploidy.

\section{Materials and Methods}

Source of oocytes. Mice, C57 × CBA F1 and 3-6 weeks of age, were induced to superovulate by i.p. injection of 7.5 i.u. PMSG (Folligon: Intervet, Lyppard Chemicals, South Australia) and hCG (Chorulon: Intervet, Lyppard Chemicals) $48-52 \mathrm{~h}$ apart. The mice were killed $14-14.5 \mathrm{~h}$ after hCG and the oviducts were collected in PB1 medium (Whittingham, 1974) supplemented with $5 \%$ heat-inactivated human serum and $5 \mathrm{mg}$ bovine serum albumin/ml (BSA: Fraction V: Sigma Chemical Co., St Louis, MO, USA). Cumulus masses were released into a solution of hyaluronidase ( $300 \mathrm{IU} / \mathrm{ml}$ : bovine testis type IS H 3506, Sigma) in the same medium and cumulus-free oocytes were washed in supplemented PBI medium. 
Freezing. The methods used for freezing and thawing were similar to those previously described by Whittingham et al. (1979). Cumulus-free oocytes were transferred to a dish of $1 \cdot 5 \mathrm{M}$-dimethylsulphoxide (DMSO, BDH Chemical Ltd, Poole, Dorset, UK) in supplemented PB1 medium on ice. During this equilibration time 20-50 oocytes were loaded into pre-cooled $\left(4^{\circ} \mathrm{C}\right) 0.25$ - $\mathrm{ml}$ plastic straws (IMV Elders Breeders, Victoria, Australia) containing the same medium. After equilibration for $10 \mathrm{~min}$ the loaded straws were placed in a Minicool Cell Freezer (Minicool AS25, France; supplier Liquid Air, South Australia) at $0^{\circ} \mathrm{C}$. The straws were cooled at $2^{\circ} \mathrm{C} / \mathrm{min}$ to $-7^{\circ} \mathrm{C}$. Ice formation was induced 1 min later by an automatic seeding device which was routinely monitored and when necessary the straws were manually seeded using a pair of forceps prechilled in liquid nitrogen. At 5 min after seeding, straws were slowly cooled at $0.3^{\circ} \mathrm{C} / \mathrm{min}$ to $-40^{\circ} \mathrm{C}$, equilibrated for $15 \mathrm{~min}$ then rapidly chilled to $-110^{\circ} \mathrm{C}$. The straws were then transferred directly to liquid $\mathrm{N}_{2}$ and stored for periods between $12 \mathrm{~h}$ and 3 weeks.

Thawing and dilution of cryoprotectant. The oocytes were thawed rapidly $\left(2500^{\circ} \mathrm{C} / \mathrm{min}\right)$ by plunging the straws directly from liquid $\mathrm{N}_{2}$ into a water bath at $37^{\circ} \mathrm{C}$. As soon as thawing was complete the contents of the straws were released into 1.5 M-DMSO in Medium PB1 supplemented with $5 \mathrm{mg} \mathrm{BSA} / \mathrm{ml}$ at room temperature and morphologically normal oocytes were collected. DMSO was diluted from these oocytes at room temperature in three 10 min equimolar steps ( $1.0 \mathrm{M}, 0.5 \mathrm{M}$ and Medium PB1). Oocytes which failed to rehydrate normally were discarded.

In-vitro fertilization and culture. Fertilization and culture was carried out in a bicarbonate-buffered HTF culture medium ( $\mathrm{HCO}_{3}-\mathrm{HTF}$; Quinn et al., 1985) containing $5 \mathrm{mg} \mathrm{BSA} / \mathrm{ml}$. Microdrops for culture and $0.5 \mathrm{ml}$ drops for fertilization were placed in plastic culture dishes (Falcon, Lincoln Park, NJ, USA), overlaid with oil (liquid paraffin colourless (Heavy): $\mathrm{BDH}$, Poole, UK) and equilibrated overnight in an humidified atmosphere of $5 \% \mathrm{CO}_{2}, 5 \% \mathrm{O}_{2}$ and $90 \% \mathrm{~N}_{2}$ before use. All subsequent incubations and cultures were carried out in this atmosphere at $39 \% \mathrm{C}$.

The detailed procedures for in-vitro fertilization of mouse ova have been described elsewhere (Quinn \& Whittingham, 1982). Briefly, each cauda epididymidis was removed from a mature $(\mathrm{C} 57 \times \mathrm{CBA}) \mathrm{FI}$ male and placed in a fertilization dish (as above). Needles were used to release the spermatozoa into the medium and allowed to disperse for $15 \mathrm{~min}$ in the incubator. The sperm concentration was then determined and a suitable aliquant added to the fertilization dishes, providing a final concentration of $2 \times 10^{6}$ spermatozoa/ml. The dishes were then incubated for $\mathrm{I}-2 \mathrm{~h}$ to facilitate capacitation. Frozen-thawed and freshly collected cumulus-free control oocytes were washed in fresh culture medium and added to the sperm suspensions. After $5 \mathrm{~h}$ the ova were removed, washed twice in fresh media and transferred to microdrops for further culture.

Experiment 1: in-vitro development of frozen-thawed oocytes. Frozen-thawed mouse ova were examined for cleavage to the 2 -cell stage $20 \mathrm{~h}$ after being removed from the fertilization drops and placed in culture. Approximately half of the 2-cell embryos were transferred to the oviducts of pseudopregnant recipients (data not presented) and the remainder were cultured for a further $90 \mathrm{~h}$ and the numbers which developed to the expanded blastocyst stage were recorded.

Experiment 2: assessment of fertilization. At $58 \mathrm{~h}$ after being placed in culture, inseminated oocytes were transferred to a specially constructed microscope slide which allowed clear visualization of pronuclei in the presence or absence of a second polar body. The slide consisted of a rectangle of Perspex $(75 \times 25 \mathrm{~mm})$ with a hole, diameter $20 \mathrm{~mm}$, drilled through its centre. Half a siliconized (Sigmacote: Sigma Chemical Co.) microscope slide was attached to the Perspex with paraffin wax to ensure a water-tight seal. Several drops of Hepes-HTF medium were placed on the slide and covered with oil.

Using a Zeiss or Nikon inverted microscope with Nomarski optics the characteristics of fertilization were assessed (see Table 1).

Statistics. The data from replicate experiments were combined and comparisons were then made using $\chi^{2}$ analysis.

Table 1. Microscopic parameters of fertilization

\begin{tabular}{lcc}
\hline & $\begin{array}{c}\text { No. of } \\
\text { pronuclei }\end{array}$ & $\begin{array}{c}\text { 2nd polar } \\
\text { body }\end{array}$ \\
\hline Normal fertilization & 2 & Yes \\
Unfertilized & 0 & No \\
Digynic & 3 & No \\
Diandric & 3 & Yes \\
Digynic + diandric & $>3$ & No \\
Polyspermic & $>3$ & Yes \\
\hline
\end{tabular}

\section{Results}

\section{Recovery, survival and development of oocytes after freezing and thawing}

From a total of 690 cumulus-free frozen-thawed oocytes, $608(88 \%)$ were recovered from the freezing straws of which $421(69 \%)$ appeared morphologically normal (Table 2). After transfer 
from insemination droplets and $20 \mathrm{~h}$ of culture, significantly fewer $(P<0.001)$ frozen-thawed eggs cleaved to the 2-cell stage compared to fresh cumulus-free control eggs. However, the number of 2-cell embryos forming blastocysts after $90 \mathrm{~h}$ in culture was not different between the two groups (Table 2).

Table 2. The effect of freezing and thawing on in-vitro development of mouse oocytes*

\begin{tabular}{|c|c|c|c|c|c|}
\hline Treatment & $\begin{array}{l}\text { No. of } \\
\text { eggs } \\
\text { frozen }\end{array}$ & $\begin{array}{l}\text { No. of } \\
\text { eggs } \\
\text { recovered }\end{array}$ & $\begin{array}{l}\text { No. of } \\
\text { eggs } \\
\text { surviving }\end{array}$ & $\begin{array}{c}\% \text { Eggs } \\
\text { forming } \\
2 \text {-cell } \\
\text { stage }\end{array}$ & $\begin{array}{c}\% \text { 2-cell } \\
\text { embryos } \\
\text { forming } \\
\text { blastocysts }\end{array}$ \\
\hline Control & - & 392 & 382 & 79 & 78 \\
\hline Frozen-thawed & 690 & $608(88 \%) \dagger$ & $421(69 \%) \ddagger$ & 46 & 75 \\
\hline
\end{tabular}

*Data are for 5 replicates of each treatment.

†Expressed as a \% of eggs frozen.

$\$$ Expressed as a \% of eggs recovered.

\section{Assessment of fertilization}

After $6-8 \mathrm{~h}$ of culture, a total of 360 frozen-thawed eggs and 350 control eggs were examined for evidence of fertilization. Significantly fewer $(P<0.001)$ frozen-thawed than control eggs underwent sperm penetration and/or male pronucleus formation (Table 3). Of those that did fertilize, the number undergoing normal fertilization, as signified by the presence of two pronuclei and a second polar body, was also significantly less $(P<0.001)$ in the frozen-thawed group (Table 3). This difference was characterized by a significant $(P<0.001)$ increase in the frequency of polyploidy in the frozen-thawed eggs (Table 3).

Table 3. The effect of freezing and thawing on in-vitro fertilization of mouse oocytes*

\begin{tabular}{lcccccc}
\hline & \multicolumn{6}{c}{ No. of oocytes } \\
\cline { 2 - 7 } Treatment & Total & $\begin{array}{c}\text { Fertilized } \\
(\%) \dagger\end{array}$ & $\begin{array}{c}\text { Normally } \\
\text { fertilized } \\
(\%)_{+}^{\dagger}\end{array}$ & $\begin{array}{c}\text { Polyploid } \\
(\%)+\end{array}$ & $\begin{array}{c}\text { Partheno- } \\
\text { genetic } \\
(\%) \dagger\end{array}$ & $\begin{array}{c}\text { Fragmented } \\
(\%) \dagger\end{array}$ \\
\hline Control & 350 & $298(85)$ & $286(96 \cdot 3)$ & $12(3 \cdot 7)$ & $1(0.015)$ & $5(1 \cdot 4)$ \\
Frozen-thawed & 360 & $228(63)$ & $191(83 \cdot 7)$ & $37(16 \cdot 2)$ & $1(0 \cdot 02)$ & $9(2 \cdot 5)$ \\
\hline
\end{tabular}

*Data are for 5 replicates of each treatment.

$\dagger$ Expressed as a \% of total oocytes.

Expressed as a \% of oocytes fertilized.

There was a difference between the percentage of frozen-thawed oocytes that cleaved to the 2-cell stage in Exp. 1 (46\%) (Table 2) and the percentage supporting the formation of pronuclei in Exp. $2(63 \%)$ (Table 3). This discrepancy was consistent with the rate of polyploidy; our experience is that polyploid eggs cleave to the 2-cell stage at a similar rate and frequency as normally fertilized control eggs (unpublished observations). This difference was not apparent in control eggs.

Parthenogenetic activation was evident in one oocyte from each group. The parthenogenomes both contained one pronucleus and no second polar body. The number of oocytes that fragmented 
during this period of culture was higher in the frozen-thawed group although this difference was not significant (Table 3 ).

\section{Source of polyploidy}

Examination of the polyploid eggs demonstrated that the significant increase in the frequency of polyploidy in the frozen-thawed oocytes could be attributed to failure of the fertilized egg to extrude a second polar body. The frequency of digynic polyploidy was $11.8 \%$ in the frozen-thawed group and $1.3 \%$ in controls $(P<0.001$; Table 4$)$. The difference in the incidence between the two groups of diandric polyploidy was not significant $(P>0.05$; Table 4$)$. The proportion of digynic to diandric oocytes in the two groups was 27:9 for frozen-thawed eggs and 4: 7 for control eggs. One tetraploid embryo of both digynic and diandric origin was seen in each group.

Table 4. The source of polyploidy in frozen-thawed mouse oocytes after fertilization in vitro $\dagger^{\dagger}$

\begin{tabular}{lccccc}
\hline & $\begin{array}{c}\text { Total no. } \\
\text { of eggs }\end{array}$ & \multicolumn{4}{c}{ Polyploidy (\%) $\neq$} \\
\cline { 3 - 6 } Treatment & fertilized & Total & Digynic & Diandric & Both \\
\hline Control & 298 & $12(3 \cdot 7)$ & $4(1 \cdot 3)$ & $7(2 \cdot 3)$ & $1(0 \cdot 3)$ \\
Frozen-thawed & 228 & $37(16 \cdot 2)$ & $27(11 \cdot 8)^{*}$ & $9(3 \cdot 9)$ & $1(0 \cdot 4)$ \\
\hline
\end{tabular}

tData are for 5 replicate experiments.

$\Varangle$ As \% of eggs fertilized.

${ }^{*} P<0.001$ compared to control value.

\section{Discussion}

Frozen-thawed mouse oocytes have a decreased rate of fertilization and an increased frequency of polyploidy (Glenister et al., 1987; present study). However, the subsequent development of in-vitro (present study) and in-vivo (Glenister et al., 1987) derived embryos from frozen-thawed oocytes was not compromised compared to controls.

Freezing and thawing resulted in a decreased number of eggs that cleaved to the 2-cell stage after in-vitro fertilization when compared to controls $(46 \%$ vs $79 \%)$. Largely responsible for this effect was a decreased ability of spermatozoa to penetrate and/or form a pronucleus in the cytoplasm of a frozen - thawed oocyte $(63 \%$ vs $85 \%)$. The explanation for this decreased fertilization rate of frozen-thawed oocytes remains unclear but it is possible that freezing and thawing may have resulted in a change in the structure of the zona and/or vitellus which may have inhibited sperm entry. Support for this explanation was the observation that frozen-thawed unfertilized oocytes demonstrated large numbers of spermatozoa bound to the zona pellucida which made them readily distinguishable from those which had fertilized. The premature release of cortical granules by frozen-thawed oocytes may also have contributed to this reduction in the rate of fertilization. The possibility that spermatozoa entered the cytoplasm of frozen-thawed oocytes but failed to form pronuclei must also be considered. Quinn et al. (1982) showed that frozenthawed zona-free hamster oocytes had a reduced ability to support sperm head decondensation and male pronuclei formation when fertilized by human spermatozoa. It is possible that a similar phenomenon contributed to the reduced rate of fertilization of frozen-thawed mouse oocytes seen in this study. 
Glenister et al. (1987) suggested that the failure of frozen-thawed mouse oocytes to undergo cleavage to the 2-cell stage may be related to the requirement for a post-thaw recovery period as previously reported for mouse embryos (Whittingham \& Anderson, 1976). Attempts to improve cleavage rates by pre-incubation of unfertilized oocytes for up to $1 \mathrm{~h}$ were not successful and longer periods appeared to affect the fertilization rate adversely (unpublished observations). Further studies are, therefore, required to delineate the exact cause(s) of reduced fertilization rates in frozen-thawed mouse oocytes.

The difference in the rates of fertilization observed in Exp. 1 (Table 2) and Exp. 2 (Table 3) suggest that freezing and thawing may interfere with pronuclear migration and/or the events necessary for normal syngamy. This possibility is currently under investigation.

The increased frequency of polyploidy in frozen-thawed eggs reported in this study $(16 \cdot 2$ vs $3 \cdot 7 \%)$ is in agreement with the findings of Glenister et al. (1987) $(15 \cdot 8$ and $8 \cdot 3 \%)$. Frozen-thawed human oocytes were also associated with a higher incidence of polyploidy (20 and $40 \%$ ) when frozen in DMSO or propanediol, respectively (Al Hasani et al., 1987). This is considerably higher than the rate of polyploidy reported after in-vitro fertilization of fresh human oocytes (10\%: Van der Ven, 1985; 1-4\%: Mahadevan \& Trounson, 1984).

While Glenister et al. (1987) also found more digynic than diandric oocytes in the small number of chromosome spreads which they were able to analyse, this current study is the first which has determined the exact source of polyploidy in frozen-thawed mouse oocytes. It is clear that the increased incidence of polyploidy primarily arises from the retention of the second polar body (digyny) and not from an increased rate of polyspermic fertilization. This suggests that freezing and thawing does not impair the block to polyspermy or damage the zona and/or vitellus so as to allow the entry of supernumerary spermatozoa.

The causes of polyspermy, i.e. high sperm concentrations, high doses of PMSG (Maudlin \& Fraser, 1977) and oocyte immaturity (Van der Ven et al., 1985), are well documented. Digynic eggs, on the other hand, are not so commonly produced. Tagaki \& Sasaki (1976) obtained an increased frequency of digyny in superovulated eggs from natural matings of $\mathrm{A} / \mathrm{He}$ strain mice and other strains have a large proportion of eggs that fail to extrude the second polar body (Beatty, 1970). Why frozen-thawed eggs do not extrude the second polar body is not entirely clear. Maro et al. (1984) showed that disruption of cortical actin and cytochalasin D prevented second polar body formation and pronuclear migration in mouse oocytes fertilized in vitro. In other studies, oocytes activated by ethanol at various post-ovulatory ages demonstrated an age-related effect on the type of parthenogenome formed (Webb et al., 1986). Oocytes activated at 12-14 h after hCG formed a haploid pronucleus and second polar body but activation of older oocytes resulted in parthenogenomes without a polar body. This transition coincided with the age-related loss of the actin-rich area at the site of polar body formation. Further, ultrastructural studies on frozen-thawed 8-cell mouse embryos showed a loss of microfilaments compared with control embryos (Bernart et al., 1987). The relationship between actin and the effects of freezing and thawing requires further investigation.

In summary, the results obtained in this study using a slow freeze to $-40^{\circ} \mathrm{C}$-rapid thaw protocol are comparable to the slow freeze to $-80^{\circ} \mathrm{C}$ and slow thaw method previously described by Whittingham (1977). However, the significant reduction in fertilizing ability and increased incidence of fertilization abnormalities in frozen-thawed mouse oocytes suggest that until many of these problems are solved the routine cryopreservation of human oocytes is not justified and could be expected to yield poorer pregnancy rates than those currently obtained from the transfer of frozen embryos.

This work was supported by a project grant from The South Australian Health Commission. We thank The Animal Ethics Committee of The Queen Elizabeth Hospital for the provision of facilities; Tina Kopsaftis for expert technical assistance; and Carol Burford for typing the manuscript. 


\section{References}

AI Hasani, S., Diedrich, K., van der Ven, H., Reiniekce, A., Hartje, M. \& Krebs, D. (1987) Cryopreservation of human oocytes. Human Reprod. 2, 696-700.

Beatty, R.A. (1970) The genetics of the mammalian gamete. Biol. Rev. 45, 73-119.

Bernart, W., Rabe, T., Schleiermacher, E., AntonLamprecht, I. \& Runnebaum, B. (1987) Freezingthawing behaviour and cell membrane ultrastructure of mouse embryos pre-cultured in B2-Menezo medium before cryopreservation. Human Reprod. 3 , $679-687$.

Chen, C. (1986) Pregnancy after human oocyte cryopreservation. Lancet 1,884886 .

Glenister, P.H., Wood, M.J., Kirby, C. \& Whittingham, D.G. (1987) Incidence of chromosome anomalies in first-cleavage mouse embryos obtained from frozenthawed oocytes fertilized in vitro. Gamete Res. 16, 205-216.

Mahadevan, M.M. \& Trounson, A.O. (1984) The influence of seminal characteristics on the success rate of human in vitro fertilization. Fert. Steril. $\mathbf{4 2}$, $400-405$.

Maro, B., Johnson, M.H., Pickering, S.J. \& Flach, G. (1984) Changes in actin distribution during fertilization of the mouse egg. J. Embryol. exp. Morph. 81, $211-237$.

Maudlin, I. \& Fraser, L.R. (1977) The effect of PMSG dose on the incidence of chromosome anomalies in mouse embryos fertilized in vitro. J. Reprod. Fert. 50 , 275-280.

Quinn, P. \& Whittingham, D.G. (1982) Effect of fatty acids on fertilization and development of mouse embryos in vitro. $J$. Androl. 3, 440444.

Quinn, P., Barros, C. \& Whittingham, D.G. (1982) Preservation of hamster oocytes to assay the fertilizing capacity of human spermatozoa. J. Reprod. Fert. 66, $161-168$.
Quinn, P., Kerin, J.F. \& Warnes, G.M. (1985) Improved pregnancy rate in human in vitro fertilization with the use of a medium based on the composition of human tubal fluid. Fert. Seril. 44, 493-498.

Takagi, N. \& Sasaki, M. (1976) Digynic triploidy after superovulation in mice. Nature, Lond. 204, 278-281.

Trounson, A.O., Leeton, J.R., Wood, C., Webb, J. \& Wood, J. (1981) Successful human pregnancies by in vitro fertilization and embryo transfer in the controlled ovulatory cycle. Science, N.Y. 212, 681-682.

Van der Ven, H.H., Al Hasani, S., Diedrich, K., Hamerich, J., Lehmann, F. \& Krebs, D. (1985) Polyspermy in in vitro fertilization of human oocytes: frequency and possible causes. Ann. N.Y. Acad. Sci. 442, 88-95.

Van Vem, J.F.H.M., Siebzehnrübl, E.R., Schuh, B., Koch, R., Trotnow, S. \& Lang, N. (1987) Birth after cryopreservation of unfertilized oocytes. Lancet ii, 752-753.

Webb, M., Howlett, S.K. \& Maro, B. (1986) Parthenogenesis and cytoskeletal organization in ageing mouse eggs. J. Embryol. exp. Morph. 95, 131-145.

Whittingham, D.G. (1974) Embryo banks in the future of developmental genetics. Genetics, Princeton 78, 395- 402 .

Whittingham, D.G. (1977) Fertilization in vitro and development to term of unfertilized mouse oocytes previously stored at $-196^{\circ} \mathrm{C}$. J. Reprod. Fert. 49, 89-94.

Whittingham, D.G. \& Anderson, E. (1976) Ultrastructural studies of frozen-thawed 8-cell mouse embryos. J. Reprod. Fert. 48, 137-140.

Whittingham, D.G., Wood, M., Farrant, J., Lee, H. \& Halsey, J.A. (1979) Survival of frozen mouse embryos after rapid thawing from $-196^{\circ} \mathrm{C}$. J. Reprod. Fert. 56, 11-21.

Received 10 June 1988 